\title{
The Rule of Law in Emerging Urban Communities
}

\author{
Jie Wei ${ }^{1}$, Xinxing Liu ${ }^{1, *}$ and Peng Nai ${ }^{1}$ \\ ${ }^{1}$ School of Law, Yunnan University of Finance and Economics, Kunming, Yunnan, 650000, China \\ *Corresponding author. Email: 201902210672@stu.ynufe.edu.cn
}

\begin{abstract}
Based on participation and observation, this work made a micro description of two governance events in an urban emerging community in recent years. Taking these events as the starting point, it analyzes the governance system and governance logic of such communities and emphasized the process and effect of legal participation in the governance of urban emerging communities, to put forward thoughts and opinions on the direction of rule of law in urban emerging communities. This work found that the law provides the most basic order guarantee for the community, constructed the community organization system, endowed the legitimacy of community autonomy, and created the possibility for community autonomy to obtain other resources.

However, it is still difficult to form a stable and harmonious community order by law alone. This work holds that only with the help of the institutional role and incentive effect of law to promote the real formation of "organic unity" within the community, can the community finally create and sustain the version of harmony and beauty.
\end{abstract}

Keywords: Urban emerging community, Rule by law, Autonomy, Community solidarity

\section{INTRODUCTION}

Since 2012, China's urbanization process has been tremendously advanced, and "building a social governance pattern of co-construction, co-governance and co-sharing" has become the general policy of grass-roots governance. The term urbanization refers to the transfer of rural population to small towns and cities, strengthening the infrastructure construction of small towns and the transformation of "villages in the city". "Village in the city", as the name suggests, refers to the areas that are classified into urban administrative divisions in the process of urban expansion and still live after villagers become urban residents. These areas often have low living standards and are incompatible with modern cities. The process of "urbanization" is accompanied by the disintegration and reconstruction of traditional village communities, as well as the breaking and reconstruction of order. "Co-construction, co-governance and co-sharing" mainly refers to the joint participation of the state, society and individuals, and the combination of rule of law, autonomy and rule of virtue. This governance model is the clearest expression of the "pluralism" view of the rule of law, and it is also the concentrated embodiment of the Chinese characteristics of the rule of law. Taking two governance events in an emerging urban community three years apart as clues, this work attempts to explain the process and ways of the rule of law participating in community governance, and reveals three problems that must be paid attention to in the construction of a harmonious community with the combination of rule of law, autonomy and rule of virtue.

\section{EPITOME OF URBAN EMERGING COMMUNITY GOVERNANCE PRACTICE}

\subsection{Overview of study sample}

Where the "Xiaoba Community" adjacent research team is located, it was transformed and established by four "villages in the city" 16 years ago. The area under its jurisdiction is 0.46 square kilometers, with 11000 households and more than 30000 people. Due to the transformation from the "village", there are both old residential buildings and shanty towns (temporary buildings and simple houses) and new high-rise houses in the community. There are urban aborigines, rural aborigines in cities, newly relocated township people and migrant workers. This community is just one of tens of millions of ordinary communities. It is an example of many "village in the city" reconstruction projects, but it is also the epitome of the rapid progress of urbanization. Two events attracted the attention of the research team.

\subsection{Failed autonomy practice and successful autonomy practice}

In 2016, all the owners of "Maxianying No. 1" neighbourhood in the community established the "owners' committee" in accordance with the law in order to receive the compensation for the acquisition of community land by the government for road widening. It is pertinent to note that "community" and " neighbourhood" are two different concepts. "Community" generally refers to the jurisdiction 
of a community residents committee; "neighbourhood" refers to the building (or building group) constructed by the same builder. A community will contain multiple " neighbourhoods". After the compensation is transferred to the collective account of the owners' committee, there are often fierce contradictions between the owners' committee and the owners because of compensation management, expenditure and other problems. In 2019, when the term of the owners' committee expires, the owners have no intention of general election, so owners' committee was dissolved. Since then, no community owners' committee has been established in the neighbourhood. Only five highrise residential areas in the whole community have property service companies, and other old buildings and shanty towns generally do not have property service companies. Communities with low property service fees or no property service often have depressed courtyards, aging infrastructure, occupied roads, blocked fire passages, dirty environment and no access control. Residents here even call themselves "rotten people's neighbourhood".

One afternoon in December 2020, the residents of 9 and 11 buildings of "Maxianying No. 1" neighbourhood held the establishment meeting of residents' autonomous group in the courtyard, and 119 residents elected 10 members of the autonomous group. The reason is that several households want to improve the "dirty, messy and poor" environment of neighbourhood, and take the initiative to propose to the community residents committee (hereinafter referred to as "neighborhood committee") to establish an autonomous group to carry out the transformation project. The neighborhood committee first sent staff to conduct a questionnaire survey on the willingness of the residents of the two buildings to establish an autonomous group. After knowing that most residents have this intention, the neighborhood committee convened everyone to hold an election meeting for the establishment of an autonomous group and established the first residents' autonomous group in the community. Greening, monitoring, access control, vehicle parking and other issues generally concerned by residents were put forward and discussed at the meeting. After the establishment of the group, two community environmental transformation meetings were held successively. Except for the residents whose houses were vacant for a long time and did not attend, the transformation consent was signed on the basis of the consent of $70 \%$ of the residents. After that, the autonomous group submitted the transformation plan to the sub district office through the neighborhood committee, and with the help and support of the neighborhood committee, won the support of the special fund for "small practical things for people's livelihood" of the sub district office. At the same time, under the coordination of the neighborhood committee, the property service company has also gladly undertaken part of the transformation funds. Finally, each household shared 200 yuan (100 yuan for difficult household registration; two houses were vacant for a long time, unwilling to pay or did not pay) to complete the transformation. The reconstructed community: the vehicle parking area and leisure activity area are reasonably planned, the access channels and remote corners are equipped with monitoring, the access control equipment is updated, the greening and environmental sanitation are improved, and the public space is enlarged. Residents often get together to carry out leisure and entertainment activities, which greatly improves their living experience. After the establishment of the autonomous group, the daily needs of residents have been reflected in a timely manner. In the process of further solving the problems such as overheated roofs, lack of street lamps and insufficient green plants, a tripartite negotiation model of autonomous group, neighborhood committee and property management has been gradually formed. The contradiction between residents and property has been alleviated, and the relationship with neighborhood committees is closer than in the past.

\section{GOVERNANCE SYSTEM OF EMERGING URBAN COMMUNITIES}

\section{1. "Residents committee" as the real end of the bureaucratic system}

Residents committees, residents and property are the main governance subjects of the modern communities. According to the Constitution of the People's Republic of China and relevant laws and regulations on urban community management, the urban community is in the charge of the people's Government of its jurisdiction. In addition, the "sub district office" sent by the government guides the community mass autonomous organization "community residents committee" to carry out specific work. The sub district office is at the end of the bureaucratic system. All kinds of public management affairs are assigned by the superior administrative organs at all levels, and finally gathered at the grass-roots level. These affairs are specifically implemented by the sub district office, widely involving people's daily affairs such as clothing, food, housing and transportation, weddings and funerals. According to the latest national statistics, by the end of 2019, there were 8519 sub district offices in China, and the urban population exceeded 800 million. Although the sub district office is at the end of the hierarchy, it has a large scope of power. It is precisely because of "more management" that it is easy to "fail to manage". Therefore, the necessity and importance of setting up residents committees are highlighted.

The law stipulates that community residents' committees shall be established in the range of 100-700 households, but the number of households under the jurisdiction of neighborhood committees in densely populated areas actually exceeds 1000. The legal responsibilities of the residents committee: on the one hand, it undertakes the publicity of laws and policies and assists the sub district office in the work assigned by the government. On the other hand, it undertakes the public affairs management of community residents, public welfare services, as well as mediating community disputes and assisting in public 
security maintenance. The residents committee is also a communication bridge between residents and administrative organs, and is responsible for reflecting public opinion to administrative organs. Although the law defines the neighborhood committee as an autonomous organization, we believe that the neighborhood committee is actually an extension of the neighborhood office and the end of the real administrative power. Obviously, the residents committee is not a bureaucratic organizational structure, and the community workers do not belong to civil servants, but their organizational operation and functional division are actually constructed to connect with the task assignment of the sub district office, and the community workers are also subsidized by the finance. As an autonomous organization, the residents committee is alienated from the residents, but closely linked with the sub district office.

\subsection{Owners' committee and property company}

Besides the residents committees, there are two types of statutory organizations in the community: the "owners' committee" (an autonomous organization elected by the owners' assembly) formed based on the differentiated ownership of buildings in the civil law, and the community property service enterprise formed based on the property service contract. In fact, owners' committees and property service companies have more direct contact with residents. In some communities, mature owners' committees or highquality property service companies can greatly help community governance. However, in more communities, contradictions and disputes are the normal relationship between owners and property companies, which essentially belongs to the balance between low price and high quality. The situation of the owners' committee is more complex. Although the law clearly stipulates the establishment and activities of the owners' committee and encourages and supports the establishment of the owners' committee, there are many failure cases. The management scope of the owners' committee is large, and some also involve the distribution and management of the common part of the operating income of the property. It not only needs to formulate regulations and standardize the performance according to law, but also needs a perfect supervision mechanism. Many neighborhoods have indeed established owners' committees, but they have no substantive role in form. On the contrary, some neighborhoods have caused more contradictions because of the establishment of owners' committees.

\subsection{Residents' autonomous group}

The law defines the residents' autonomous group as a branch of the residents committee, and the residents committee may set up residents' autonomous groups. The residents' autonomous group is also autonomous in nature, but it only involves the residents of a building or a courtyard in the community, which is smaller than the owners' committee. The residents' autonomous group does not involve the distribution of the operating income of the common part of the property, avoiding major differences of interests. The establishment of the first residents' autonomy group of "Xiaoba community" also fully reflects the characteristics of this kind of organization. It is born entirely to solve the immediate practical problems and is a primary exploration that cannot be skipped in community autonomy.

In order to facilitate work, the residents committee will also set up mass liaison officers such as building heads and household heads to help publicize affairs and collect information. Some residents' committees will issue symbolic subsidies, and some will provide services purely free of charge. There are 50 buildings in "Xiaoba community", each with one building head. The building heads often walk among the residents and have a better understanding of the residents. In order to learn about the views and wishes of residents of "Xiaoba community" on the establishment of the autonomous group, the research group interviewed and investigated 50 building heads. When asked "whether they agree to the establishment of an autonomous group", only three held a negative opinion (see Table 1).

Table 1. Opinions on the establishment of an autonomous group

\begin{tabular}{|c|c|c|}
\hline Option & Quantity & Proportion \\
\hline Yes & 47 & $94 \%$ \\
\hline No & 3 & $6 \%$ \\
\hline
\end{tabular}

Each head of the building also put forward opinions on the environment, safety, infrastructure, resident relations, property services and other problems existing in the community. When asked "whether the establishment of an autonomous group is conducive to the solution of the problem,"46 expressed positive opinions (refer to Table 2).

Table 2. The evaluation on the self-governing group

\begin{tabular}{|c|c|c|}
\hline Option & Quantity & Proportion \\
\hline YES & 46 & $92 \%$ \\
\hline NO & 4 & $8 \%$ \\
\hline
\end{tabular}

It can be seen that the successful practice of the first residents' autonomous group of "Xiaoba community" has had a positive effect within the community. The successful practice may encourage the establishment of more autonomous groups, and also shows that community autonomy must start from a small scope.

\section{CONTEXT OF RULE OF LAW IN EMERGING URBAN COMMUNITIES}

\subsection{Interaction between law and community}

The owners' committee, residents committee and residents' autonomous group all have a clear legal positioning, 
reflecting the legalization of grass-roots autonomy, which is the legislator's idea of orderly community governance. According to this idea, the community cannot only organize itself, manage and solve trivial problems by itself, but also connect its organizational system with the national administrative system. Its operation can also comply with the national policies, conform to the general policy of the state and give play to the role of a bridge between the state and society. However, compared with the real community scene, the legal provisions are abstract. The failure of the owners' committee of "Xiaoba community" and the success of the residents' autonomy group show that the power to promote the legal concept from norm to fact comes from within the community.

First, the role of community elites is obvious. The elites of emerging urban communities no longer refer to the traditional elders' authority, nor do they necessarily belong to the class above the middle class. They are often enthusiastic residents willing to participate in autonomous organizations to serve everyone. Their wishes and actions can have a substantive impact on the community. They may be young and middle-aged people who are good at communicating and coordinating with other residents and residents committees, retirees with good organizational skills, or versatile housewives. More importantly, there is no major interest difference between community elites and ordinary residents. At first, they may participate in community affairs management based on their own interests, but the process and results benefit everyone.

Secondly, most residents in the community have an urgent need to change the current situation, with clear objectives and high overlap, basically focusing on the living environment and safety order. It is easy to succeed and with low cost as long as most people are willing to contribute and share. More importantly, the social gap between residents is not too large, the problems to be solved will not cause serious differences in values, and there is no multi-interest game between residents to hinder consensus.

Finally, the guidance of the residents committee staff (social workers) helps to make the action of the autonomous group professional and standardized, and it is easier to get funds or other support from the sub district office. The establishment and long-term operation of the autonomous group cannot only share the work of the residents committee, but also be a part of the performance of the sub district office. Therefore, the sub district office and the residents committee are happy to see its success. At the same time, when most people's actions are supported by sub district office and residents committees, others are likely to be driven.

The combination of the above factors has both contingency and inevitability. Whether the emergence of community elites, the accumulation of residents' urgent needs and the unity of cognition all need the trigger and incentive of time and events. In the process of modernization and urbanization, the organic role of law on different types of communities is very obvious. Even in "acquaintances" or "semi acquaintances" communities with common life history and community habits, community authority and consensus rules, social transformation and order reconstruction must be oriented to the reconstruction of countries under the rule of law, which is the need of social integration. Therefore, community factors incompatible with laws and policies will gradually be marginalized. In short, community autonomy must be carried out on the blueprint outlined by law. Community autonomy itself is also an indispensable part of the blueprint of the rule of law.

\subsection{Legal limitations}

Conflicts, cumulative conflicts and daily disputes are obstacles to the orderly development of the community. Most of the common contradictions and disputes in the community have been brought into the scope of legal adjustment, such as violations of public security management law and criminal law, high-altitude throwing, noise intrusion, real right occupation and other violations of civil rights and interests. Some acts are infringement or illegal in nature, but have not reached the level of legal accountability. These acts include but not limit to neighborhood quarrels without physical collision, neighborhood dissatisfaction without violating the decoration ban, occasional occupation of public passages or parking spaces, slight water leakage upstairs but not repaired in time... Disputes outside the scope of legal adjustment can only be resolved outside the law, mediation disputes, resolving contradictions is also the most important function of community autonomous organizations. Disputes within the scope of legal adjustment may not be resolved by law, because the cost of resolving by law is too high.

For example, there are two major conflicts and disputes between the two buildings that set up the autonomous group recently. One is the decoration of shops on the street. The residents upstairs are worried that the construction will cause wall cracking and noise. The two sides have quarreled repeatedly, but neither party has resorted to court. The second is that the residents on the first floor of building 10 have opened an entrance to operate the mahjong room in their own courtyard wall. There are often non residents in and out, and the newly installed access control is in vain. Other residents complained repeatedly that although it was illegal to operate mahjong rooms in the community, the residents committees and sub district offices had no law enforcement power and could not ban them. The community reported to the police station maintaining public security and the superior government, that the government and the police station did not deal with the situation after investigating. Some residents in the old neighborhood have no other sources of livelihood and use their only housing resources to rent to others to play mahjong to make a living, which is not a special case in the old neighborhood. Of course, this is illegal business and has a direct impact on the living environment and feelings of other residents, but in the view of law enforcers, it will not pose a threat to society. If the 
government cannot provide them with alternative income channels, but ban them outright, it is easy to cause their dissatisfaction with the government and then lead to social events.

\subsection{Compensatory role of community autonomy}

Contradictions and disputes may come from society, individuals, or even the law itself. The law cannot solve all problems. Contradictions and disputes that cannot be solved by law are either solved by the community itself or shelved. If the community has a strong ability to resolve disputes, autonomous organizations can also win the longterm trust and recognition of residents. In order to prevent the shelved disputes from eventually turning into social conflicts, the judicial authorities now pay attention to daily guiding community mediation and cultivating community dispute resolution forces. The judiciary is deeply aware that the limitations of the law are facts, but directly telling the parties that "your dispute is outside the scope of legal adjustment" has no meaning. On the contrary, it will lead to people's disappointment with the law. Rather, it will open up ways for people to resolve disputes outside the lawsuit.

Although the "Maxianying No. 1" neighborhood autonomous group has not played a role in resolving contradictions and disputes, it has gradually become the connection point of residents' relations. Although live in the same community, the residents have no direct economic exchange relationship and have not formed a social communication relationship. Meeting without saying hello is an intuitive manifestation of the alienation of community relations in the past. However, the autonomous group has created a communication platform and opportunities for residents by holding community transformation meetings, holding "neighborhood banquets", volunteering to plant flowers and other collective activities, and the community atmosphere has become active. When residents gradually change from strangers to "acquaintances", trust and tolerance will be conducive to the resolution of community contradictions and disputes.

\section{DIRECTION OF RULE OF LAW IN EMERGING URBAN COMMUNITIES}

Carrying out targeted transformation actions, resolving contradictions and disputes and organizing collective activities are the ways and manifestations of the growth of community autonomy. The emerging urban communities we observed have no social norms that need historical and cultural accumulation, such as traditional habits, industrial norms and folk conventions. Perhaps the autonomy and interaction of residents will promote the development of these social norms, but it is not what Hayek calls "spontaneous" order. Because the institutional resources, material resources, technical resources and human resources required for the establishment and operation of community autonomous organizations do not simply come from the community. In fact, law always participates in the process of community autonomy in an explicit or implicit way.

The law provides the most basic order guarantee for the community. Theft, robbery and violent conflict rarely occur in some corners. The law also constructs the organizational system of the community, endows the legitimacy of community autonomy, creates the possibility for community autonomy to obtain other resources, and sets the road to harmony and beauty for the community. However, this is not an example of Hobbes' version of "how order is formed". After all, under the same legal background, communities that only maintain the most basic order but are neither harmonious nor beautiful exist at the same time. To build a harmonious community with the combination of rule of law, autonomy and rule of virtue, it must pay attention to three aspects.

First, law is the way of communication and connection of "stranger society". The reason why people enjoy rights and perform obligations at the same time largely stems from the awe of law. Therefore, the community relationship only relying on legal connection is alienated and loose. Such a community may be extremely peaceful, but it is difficult to call it "harmonious and beautiful". On the surface, law replaces the connection elements of traditional social "community" such as blood, geography and moral emotion, and also shapes the "combination" of new regional life such as urban emerging communities, but law cannot really become the emotional link of community connection. The real role of law is to encourage people who don't know each other to take the steps of communication, be willing to cooperate, to help each other, and to unite to make the community truly harmonious and beautiful.

Second, the legal role is limited, but community autonomy can make up for legal defects. The premise is that community autonomy can enhance the communication and connection between residents and build a communication bridge between residents, residents committees and sub district offices. In this way, the community will form a strong governance force and a good governance atmosphere. Community identity and sense of belonging will be established with the continuous enhancement of communication and connection among residents. The formation of community cohesion will make community relations more flexible and inclusive, so as to build a soft barrier for disputes and conflicts between individuals.

Third, autonomous organizations are only a form, not the establishment of autonomous organizations can promote autonomy. If the motivation for the establishment of autonomous organizations is not the real will of residents, it is difficult for autonomous organizations to maintain for a long time, let alone enhance the communication and connection among residents and create community unity and "collective consciousness". Frequent interaction, harmonious relationship and cohesive community life 
cannot only meet individual social needs, but also help to reshape individual morality.

\section{CONCLUSION}

Only with the help of the institutional role and incentive effect of law, can the community finally lead to harmony and beauty by promoting the real formation of "organic unity" within the community. When community residents genuinely participate in community construction and care about community affairs, long-term practice will recultivate the individual's sense of social responsibility. Individuals will have a more complete understanding and recognition of rights, obligations and responsibilities, and will truly understand their relationship with the collective, society and even the country.

\section{ACKNOWLEDGMENT}

This work is supported by Yunnan Philosophy and Social Science Foundation (YB2018025).

\section{REFERENCES}

[1] "Villages in cities" refer to the areas that are classified into urban administrative divisions in the process of urban expansion and where villagers still live after becoming urban residents. These areas often have low living standards and are incompatible with modern cities.

[2] "Shanty areas" refer to temporary structures and simple housings.
[3] "Community" and "neighborhood" are two different concepts. "Community" generally refers to the area under the jurisdiction of a Community Residents Committee, while "neighborhood" refers to a building (or a group of buildings) constructed by the same builder. A community may consist of several "neighborhoods".

[4] Robert Article 2 and Article 3 of the Organic Law of the Urban Residents Committees of the PRC.

[5] Robert C. Ellickson. Order Without Law: How Neighbors Settle. Su Li, translate. Beijing: China University of Political Science and Law Press, August 2003. ISBN: 9787562024446

[6] Collins, R. \& Makowsky, M. The discovery of society, 6th ed. Li Xia, translate. Beijing: Zhonghua Book Company, April 2006. ISBN: 9787101050271

[7] Zitang Fu \& Shukun Zhao. The rule of law in the developing status quo: a theoretical approach to law and society in contemporary China in its social transition. Beijing: Peking University Press, August 2013. ISBN: 9787301229538. (In Chinese)

[8] Emile Durkheim. De la division du travail social. Qu Jingdong, translate. Shanghai: SDX Joint Publishing Company, January 2017. ISBN: 9787108057921

[9] Robert D. Putnam. Bowling Alone: The Collapse and Revival of American Community. Liu Bo, Zhu Naijuan, Zhang Ziyi, etc. Translation. Beijing: Peking University Press, August 2018. ISBN: 9787562083948 